\title{
Stenosis of Gastrointestinal Stoma, CTCAE
}

National Cancer Institute

\section{Source}

National Cancer Institute. Stenosis of Gastrointestinal Stoma, CT CAE. NCI Thesaurus.

Code C143858.

A finding of narrowing of the gastrointestinal stoma (surgically created opening on the surface of the body). 